\title{
Improving the Growth Rate of Human Adipose-Derived Mesenchymal Stem Cells in Alginate/Gelatin Versus Alginate Hydrogels
}

\author{
Soheila Rezaei 1,2, Mehdi Shakibaie 3, Maryam Kabir-Salmani 2*, Mostafa Soltani Moghaddam 4, \\ Mohammad Rezvani ${ }^{5}$, Maryam Shahali ${ }^{6}$, Marzieh Naseri ${ }^{7}$ \\ ${ }^{1}$ Department of Agricultural Biotechnology, Payame Noor University, Tehran, Iran \\ ${ }^{2}$ Department of Stem Cell and Regenerative Medicine, Institute of Medical Biotechnology, National Institute of Genetic \\ Engineering and Biotechnology, Tehran, Iran \\ ${ }^{3}$ Department of Bioprocess Engineering, Institute of Industrial and Environmental Biotechnology, \\ National Institute of Genetic Engineering and Biotechnology, Tehran, Iran \\ ${ }^{4}$ Department of Stem Cell, Geneocell Science based Company, Tehran, Iran \\ ${ }^{5}$ Department of Environment, Natural Resources, Payame Noor University, Tehran, Iran \\ ${ }^{6}$ Department of Quality Control, Pasteur Institute of Iran, Tehran, Iran \\ ${ }^{7}$ Department of Molecular Medicine, Iran University of Medical Sciences, Tehran, Iran
}

${ }^{*}$ Corresponding author: Maryam Kabir-Salmani, Department of Stem Cell and Regenerative Medicine, Institute of Medical Biotechnology, National Institute of Genetic Engineering and Biotechnology, Tehran, Iran. Tel: +98-2144787464, Fax: +98-2144787395, E-mail: Maryam@nigeb.ac.ir

Received: April 06, 2015; Revised: July 11, 2015; Accepted: October 20, 2015

Background: Expansion and differentiation of stem cells relies on the soluble materials as well as the physical conditions of their microenvironment. Several methods have been studied in attempt to enhance the growth and differentiation rates of different adult stem cells extracted from different sources.

Objectives: The purpose was to improve the three-dimensional (3D) culture condition of the semi-permeable polymeric beads for encapsulation of the human adipose-derived mesenchymal stem cells (hADSCs) by modifying the ratio of the alginate-gelatin composition.

Materials and Methods: Following isolation and characterization of hADSCs by flow cytometry and their functional differentiation, encapsulation in the alginate and alginate/gelatin compositions were performed. Moreover, the stability, swelling, size frequency, growth kinetics, and cytotoxicity of the beads were measured to meet proper condition in the designed experimental and control culture conditions. Finally, the growth rates of the cells in different experimental groups and control were measured and analyzed statistically.

Results: Viability decreased in 2 and 3 percent alginate once compared to $1 \%$ alginate in beads $(p \leq 0.05)$. Moreover swelling of the beads in the alginate/gelatin compositions (50:50 and 70:30) were higher than the pure alginate beads ( $\mathrm{p} \leq$ $0.05)$. Finally, the cell growth rate in alginate/gelatin (50:50) beads was significantly higher than alginate and alginate/gelatin $(70: 30)$ beads $(\mathrm{p} \leq 0.05)$.

Conclusions: These findings suggested for the first time that the composite of alginate/gelatin beads with the ratio of 50:50 might provide a suitable culture condition for the encapsulation and in vitro expansion of the hADSCs.

Keywords: Alginate; 3D culture; Gelatin; Encapsulation; Stem cells

\section{Background}

The unique potential of the mesenchymal stem cells (MSCs) to modulate immune responses prompts their promising application in the regenerative medicine and tissue engineering. The multilineage differentiation potential of the human adipose-derived mesenchymal stem cells (hADSCs) together with the less invasive accessibility makes them a proper candidate for cell therapy $(1,2)$. Study on the application of sev- eral artificial extracellular matrices (ECMs) with different composites and their three-dimensional (3D) distribution patterns are considered as an interesting topic in attempt to improve their therapeutic capabilities (3). The exposed microenvironment of the $3 \mathrm{D}$ cultures that mimics in vivo conditions provides more effective interactions between cells and their microenvironment (4). Regarding the fact that the expansion and differentiation of adult stem cells depends on the 
different signals provided by their microenvironment, improving proliferation and differentiation of MSCs has been the topic of interest (5-7). In this regard, the applications of the artificial scaffolds and encapsulation of the cells in semi-permeable polymeric materials appeared to enhance cell growth, differentiation, and protein production $(8,9)$. Moreover, biocompatible polymers such as alginate, chitosan, and collagen together with synthetic polymers such as poly (ethylene glycol) (PEG), poly (lactic acid) (PLL), poly ( $\varepsilon^{-}$ caprolactone), and gelatin, as a natural polymer had been implemented frequently (10-14). Among these polymers, gelatin has some advantages when preparing artificial ECMs $(15,16)$. It is a water soluble biopolymer with a high biodegradation rate. Next to gelatin, sodium alginate seems to be a proper polymer. Due to its composition, it can bind to other biomaterials such as bioglass, hydroxyapatite, chitosan, and collagen to produce popular matrices in human cell cultures (17-19). Modifications of alginate concentration in 3D structure system have shown to enhance insulin production in insulin-producing cells obtained from embryonic stem cells (20). The alginate microcapsules cross-linked with $\mathrm{Ca}^{2+}$ and $\mathrm{Ba}^{2+}$ reported to provide suitable pore size to improve cell viability and protein secretion (21). However, no study was reported to compare different composites of alginate/gelatine hydrogels in order to improve the growth rate of the hMSCs.

\section{Objectives}

Based on the potential therapeutic application of hADSCs and alginate beads, the purpose of the current study was to improve the growth rate of hADSCs in the $3 \mathrm{D}$ culture condition by the addition of different ratio of the gelatin to the alginate biopolymer beads.

\section{Materials and Methods}

\subsection{Materials and Stock Preparation}

Sodium alginate (Mw: 100,000-200,000 g.mol-1, G-Content: $65-70 \%$ ) and gelatin (type A from porcine skin, 300 Bloom), indomethacin, dexamethasone, insulin, ascorbic acid, glycerol phosphate, and Isobutyl methyl xanthine were purchased from Sigma-Aldrich (St. Louis, MO, USA). Dulbecco's modified Eagle's medium (DMEM, Invitrogen, CA, USA), Fetal Bovine Serum (FBS, Invitrogen, CA, USA), and trypsin were purchased from GIBCO Invitrogen (Invitrogen, CA, USA). Fluorescent isothiocyanate (FITC)-conjugated mouse anti-human CD90, CD45 and Phycoerythrin (PE)-conjugated CD44, CD73, CD105, and CD34 purchased from Abcam, Cambridge, MA, USA). Lactate dehydrogenase (LDH) activity assay kit was from Greiner Diagnostic GmbH, Bahlingen, Germany. Glucose and lactate assay kits were from Greiner Diagnostic GmbH, Bahlingen, Germany. Other chemicals were purchased from MERCK Co. (Germany).

Alginate and gelatin stocks were prepared in DMEM. Gelatin (4\%) and alginate (4\%) were dissolved in $100 \mathrm{~mL}$ distilled water, separately. After sterilizing at $80^{\circ} \mathrm{C}$, DMEM $(2 \mathrm{X})$ was added to obtain final concentration of $2 \%(\mathrm{w} / \mathrm{v})$. Different ratios were taken from the stock solutions to prepare alginate:gelatin compositions as shown in Table 1.

\subsection{Isolation, Culture and Characterization of HADSCS}

Human adipose tissues were obtained from abdominoplasty procedures. Written informed consents were obtained from all donors and the Local Ethical Committee approved the investigational use of the tissues. Tissues were washed three times with phosphate-buffered saline (PBS) and digested with $0.1 \%$ wild collagenase (Sigma, St Louis, MO) for 50 min at $37^{\circ} \mathrm{C}$. Enzyme activity was neutralized with FBS. The neutralized cell suspensions were centrifuged at $1000 \mathrm{rpm}$ for $5 \mathrm{~min}$. Floating adipocytes were removed and the pellets of mesenchymal stem cells were filtered through the cell strainer before plating (pore size $150 \mu \mathrm{m}$, Millipore, USA). The cells were cultured in DMEM containing $100 \mathrm{U}^{\mathrm{mL}} \mathrm{m}^{-1}$ of penicillin/streptomycin and $10 \% \mathrm{FBS}$ at $37^{\circ} \mathrm{C}$ in the atmosphere containing $5 \% \mathrm{CO}_{2}$. The medium was

$\overline{\text { Table 1. Composition of alginate/gelatin suspensions and main characteristics of final con- }}$ centrations

\begin{tabular}{lccc}
\hline Compositions & Stock solution \% (w/v) & Proportions \% & Final concentration (w/v) \\
\hline Alginate/Gelatin & 1 & $100: 0$ & 1 \\
Alginate/Gelatin & $2: 2$ & $30: 70$ & $0.6: 1.4$ \\
Alginate/Gelatin & $2: 2$ & $50: 50$ & $1: 1$ \\
Alginate/Gelatin & $2: 2$ & $70: 30$ & $1.4: 0.6$ \\
\hline
\end{tabular}


replenished after $72 \mathrm{~h}$ culture. When cells reached 70$80 \%$ confluence, cultures were harvested with $0.25 \%$ trypsin-EDTA solution, resuspended in growth medium, and subcultured.

To characterize the obtained cells, cells at the third passage were harvested, resuspended in PBS, and centrifuged. About $2 \times 10^{5}$ cells were centrifuged at $300 \times \mathrm{g}$ for $5 \mathrm{~min}$ at $22^{\circ} \mathrm{C}$. The pellet was suspended in PBS and incubated for $45 \mathrm{~min}$ on ice with appropriate antibodies including fluorescent isothiocyanate (FITC)conjugated mouse anti-human CD90, CD45 and Phycoerythrin (PE)-conjugated CD44, CD73, CD105, and CD34. The labeled cells were washed with PBS and analyzed using a FACS-Calibur (Becton Dickinson, USA). An isotype control with FITC or PElabeled was included in each experiment and specific staining was measured from the cross point of the isotype with the specific antibody graph. Histograms were prepared with Win MDI 2.8 software (Scripps Institute, La Jolla, CA, USA). For adipogenic differentiation, the cells in the third passage were cultured for 2 weeks in the defined adipogenic medium, containing growth medium supplemented with $200 \mu \mathrm{M}$ indomethacin, $1 \mu \mathrm{M}$ dexamethasone, $1.7 \mu \mathrm{M}$ insulin, and $500 \mu \mathrm{M}$ isobutyle methyl zantin. In negative control, cells in the third passage were cultured in growth medium for 2 weeks and stained by Oil red. For osteogenic differentiation, the cells in the third passage were cultured for 2 weeks in the defined osteogenic medium, containing growth medium supplemented with $10 \mu \mathrm{M}$ dexamethasone, $10 \mu \mathrm{M}$ glycerol phosphate, and 0.05 g.L.- ${ }^{-1}$ ascorbic acid. In negative control, cells in the third passage were cultured in growth medium for 2 weeks and stained by Alizarin red.

\subsection{Beads Swelling and Stability Tests}

The stability of the samples was assessed in $0.9 \%$ $(\mathrm{w} / \mathrm{v}) \mathrm{NaCl}$ solution. Beads (30) were incubated in $\mathrm{NaCl}$ solution and fractured beads were counted every three days. The fracture frequency was calculated using the following formula:

$$
\text { Fracture frequency } \%=\frac{(\text { Beads fractured })_{\text {attime }}}{\text { total beads loaded }} \times 1
$$

The beads swelling were calculated based on bead weight increment in $\mathrm{NaCl}$ solution. Briefly, freshly prepared beads weighed and placed in a glass vial containing $100 \mathrm{~mL}$ of $\mathrm{NaCl}$ solution and incubated at $37^{\circ} \mathrm{C}$ followed by shaking at $110 \mathrm{rpm}$ for $5 \mathrm{~h}$. The wet weight of the swollen beads was determined by blot- ting with filter paper to remove excess moisture adhering to the surface that immediately followed by weighing on an electronic balance. At least 30 beads were measured in each experimental group. The beads swelling were calculated from the following formula, where $W_{i}$ was the initial weight of the beads and $W_{t}$ was the weight of the swollen beads:

$$
\text { Swelling } \%=\frac{W t-W i}{W i} \times 100
$$

\subsection{Preparation of Gel Beads Containing Gelatin and Alginate}

A confluent monolayer of adherent hADSCs was removed following trypsin-EDTA incubation. The cell suspensions were centrifuged at $1000 \mathrm{rpm}$ for $5 \mathrm{~min}$ at $4{ }^{\circ} \mathrm{C}$. The cell pellet re-suspended in alginate:gelatin solutions. All groups were cultured at the same cell density of $5 \times 10^{5}$ cells. $\mathrm{mL}^{-1}$ of alginate. The beads were generated by extruding the cell: alginate/gelatin mixture from a plastic syringe via $30 \mathrm{G}$ needle into a $20 \mathrm{~mL}$ bath of $\mathrm{CaCl}_{2}(100 \mathrm{mM})$, containing $145 \mathrm{mM}$ $\mathrm{NaCl}$, and $10 \mathrm{mM}$ HEPES. Formed beads were maintained in $\mathrm{CaCl}_{2}$ bath for $10 \mathrm{~min}$ at $22^{\circ} \mathrm{C}$. Generated beads washed with hank's buffer three times. The alginate beads were cultured in bacterial petri dishes in order to minimize the adhesion of cells on the excess surface. In another group, the cell culture flasks were used for 2D culture of hADSCs. All groups were cultured at the same conditions of inoculums and volume of basal medium.

\subsection{Cell Analysis Following Encapsulation}

For analysis of the viable cells following proliferation and cell growth, the supernatant was removed from the bacterial plates and beads were washed with Hank's buffer. The sodium citrate solution (100 mM in PBS) was used for decrosslinking beads at exposure time of $10 \mathrm{~min}$. The cell suspension was centrifuged at $80 \times g$ for $5 \mathrm{~min}$ and the pellet used for cell count and viability test by trypan blue method.

Glucose and lactate concentrations were measured by the glucose and lactate assay kits, as explained by the manufacturer. The cytotoxicity assay was measured by lactate dehydrogenase (LDH) activity assay kit (Greiner Diagnostic GmbH, Bahlingen, Germany), according to the guidelines of the manufacturer.

\subsection{Statistical Analysis}

All experiments were carried out in triplicate and the results were reported as the mean values. The standard deviation was calculated by Microsoft Excel soft- 
ware. One-way ANOVA was used to compare the means $(p \leq 0.05)$. All statistical calculations were carried out using SPSS software (version 16 from Softonic).

\section{Results}

\subsection{Beads Stability and Swelling}

Following 9 days of incubation, the stability of beads was decreased by $70 \%$ in alginate/gelatin $(50: 50) \quad(\mathrm{p} \leq 0.05)$ compared to that of alginate beads (Figure 1). However, no significant decrease in stability was observed in alginate/gelatin beads (70:30) $(p \leq 0.05)$ when compared to that of the alginate. Alginate beads with the ratio of 30:70 were not stable ( Figure 1 ).

Beads stability and swelling rate relationship was established. Swelling of the beads' increased by the addition of the gelatin to the alginate beads. The swelling of the alginate/gelatin (50:50) beads were $57 \%$ more than that of the alginate beads, whereas no significant difference were observed between alginate/gelatin (70:30) swelling in comparison with alginate beads $(\mathrm{p} \leq 0.05)$. Thus, it might be concluded that the size of the beads was larger in alginate/gelatin beads compared to that of the alginate beads. Furthermore, these results demonstrated that the increase in the swelling could adversely affect the stability. The data obtained from cell recovery measurements of dissolved beads as shown in (Table 1), indicated that the addition of the gelatin to the alginate solution had no considerable effect on the cellular loss (Table 1).

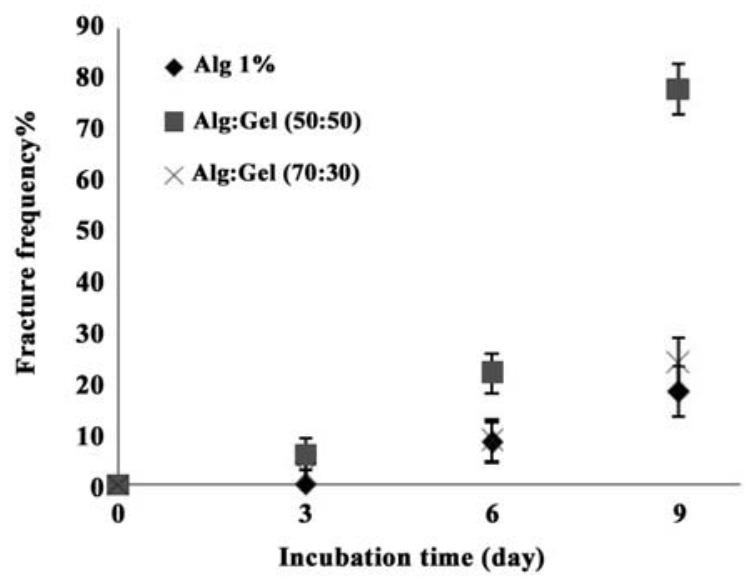

Figure 1. The influence of alginate/gelatin compositions on stability of the beads during 3,6 , and 9 days of incubation time

\subsection{Cell Characterization, Viability and Proliferation}

Flow cytometry is routinely used for the characterization of isolated cells. The results of immunophenotyping profile indicated that the cells were positive for CD90 (96.30\%), CD 105 (96.08\%), and CD73 (90.97\%), which together were considered as markers for human MSCs. The cells were negative for hematopoitic lineage and the human leukocyte markers including CD45 (0.35\%), CD31 (0.26\%), CD34 $(0.18 \%)$ (Figure $2 \mathrm{~A})$. Furthermore, the mesodermal differentiation results from Oil red (Figure 2, panel B, right side) and alizarin-red (Figure 2, panel B left side) stains confirmed the presence of lipid droplets and calcium deposits in the adipogenic and osteogenic induced differentiated cells, respectively (Figure 2, panel B). These pieces of evidence together with fibroblastic morphology and clonogenic capacity of the cells (data not shown) allowed us to conclude that the cultivated cells had the basic properties of human ADSCs (Figure 2).

The viability of hADSCs in alginate beads were determined by trypan blue method. Comparing to $1 \%$ alginate beads, the cells' viabilities were decreased by $44 \%$ and $53 \%(\mathrm{p} \leq 0.05)$ in groups cultured in $2 \%$ and $3 \%$ alginate beads, respectively (Figure 3 ). Viability of the cells in the alginate/gelatin compositions (50:50 and $70: 30$ ) was higher than $2 \%$ and $3 \%$ alginate beads (Figure 3).

The state of cellular viability was measured by direct and indirect methods. Glucose consumption as well as the formation of by-products considered as indirect methods to evaluate cells viabilityGlucose and lactate concentrations were measured in 3D culture of hADSCs to assess whether the gelatin had negative effect on the proliferation and viability of hADSCs or not. Glucose consumption increased from $131 \mathrm{mg}$. $\mathrm{L}^{-1}$ in alginate/gelatin beads (50:50) to $268 \mathrm{mg} . \mathrm{L}^{-1}$ in alginate beads, as the control (Figure 4).

Interestingly, the yield of lactate per glucose $\left(\mathrm{Y}_{\mathrm{Lac} / \mathrm{Glc}}\right)$, as an indicator of proper cell respiration, had no significant difference between the alginate beads and alginate/gelatin (70:30) beads cultures $(\mathrm{p} \leq 0.05)$. The alginate/gelatin $(50: 50)$ prepared suitable respiration condition due to the decrease in the yield of lactate per glucose $\left(\mathrm{Y}_{\mathrm{Lac} / \mathrm{Glc}}\right)$ (Table 2). The hADSCs specific growth rate was only calculated in alginate/gelatin beads because of lower proliferation in alginate and alginate/gelatin (70:30) beads. The application of lactate dehydrogenase (LDH) release for the evaluation of death and growth of human cells in 3D culture was regarded as an indirect method of cell via- 
Table 2. Calculated parameters in different compositions of the alginate/gelatin beads

\begin{tabular}{|c|c|c|c|c|c|c|}
\hline Hydrogel & $(\mu)(1 / h)$ & $\begin{array}{c}Y_{\text {Lac/Glc }} \\
\left(\mathrm{mg} \mathrm{mg}^{-1}\right)\end{array}$ & $\begin{array}{l}\text { LDH activity } \\
\left(\mathrm{U.L}^{-1}\right)\end{array}$ & Swelling (\%) & $\begin{array}{l}\text { Beads size } \\
(\mathrm{mm})\end{array}$ & Recovery (\%) \\
\hline \multirow[t]{2}{*}{ Alginate } & ----- & $0.99 \pm 0.12$ & $87 \pm 3$ & $57 \pm 5$ & $2.2 \pm 0.1$ & $88 \pm 2$ \\
\hline & $*$ & $*$ & & $*$ & & \\
\hline Alginate/Gelatin (50:50) & $0.009 \pm 0.005$ & $0.83 \pm 0.18$ & $80 \pm 5$ & $85 \pm 4$ & $3.7 \pm 0.2$ & $92 \pm 5$ \\
\hline Alginate/Gelatin (70:30) & --- & $0.87 \pm 0.1$ & $85 \pm 5$ & $69 \pm 2$ & $3.2 \pm 0.15$ & $91 \pm 4$ \\
\hline
\end{tabular}

LDH: Lactate dehydrogenase

Y Lac/Glc: Lactate/Glucose

$\mu$ : Specific growth rate $(1 / \mathrm{h})$
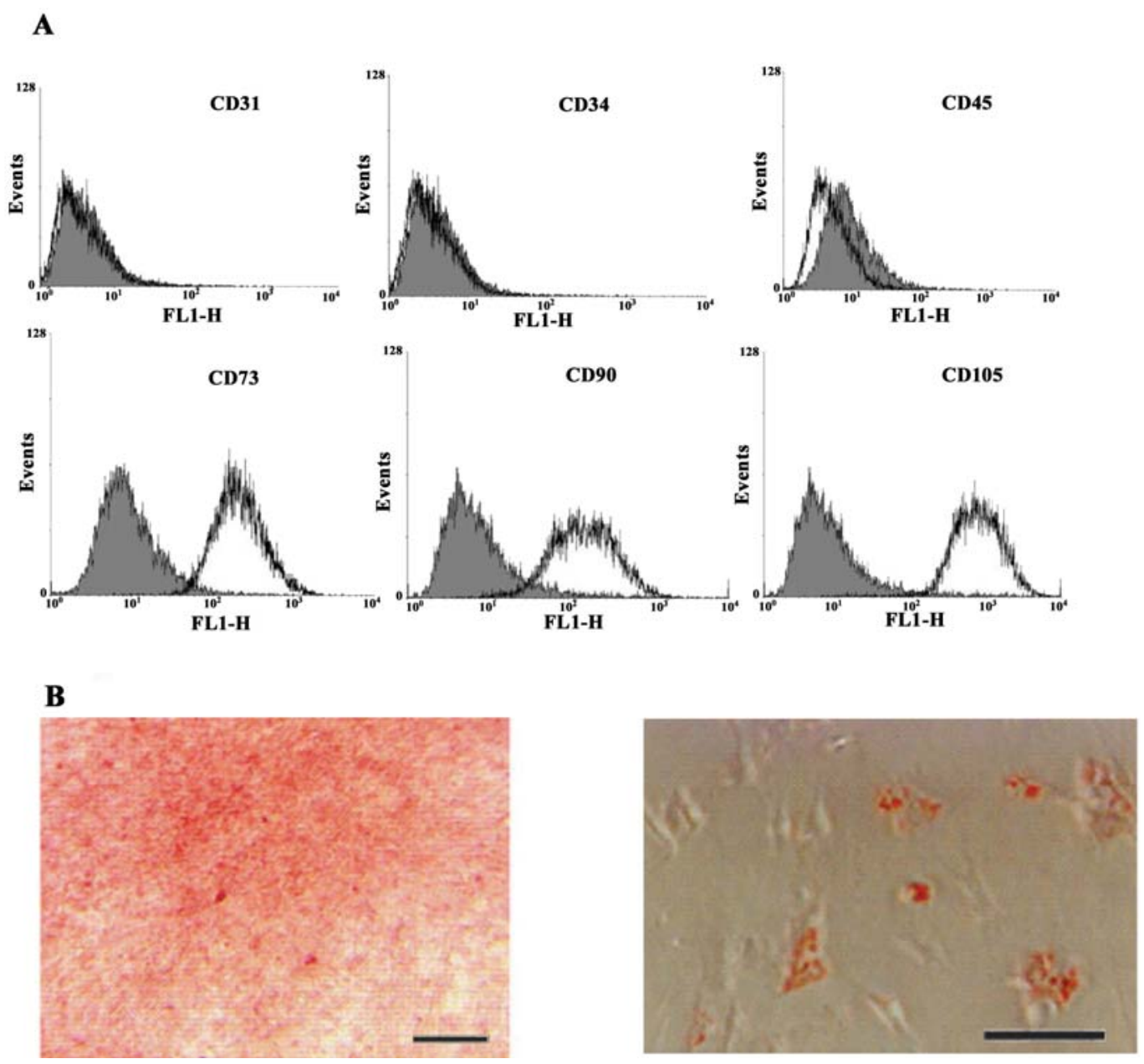

Figure 2. A: Immunophenotyping of isolated hADSCs. The isolated hADSCs in the third passage were negative for hematopoietic, and leukocyte cell markers (CD31, CD34, CD45) and positive for the mesenchymal cell markers (CD73, CD90, CD105). B: Osteogenic and adipogenic differentiation of isolated hADSCs. Osteogenic differentiation was positive for alizarin red staining (left) and the adipose droplet in differentiated cells were positive after staining with oil red (right). Scale bars $10 \mu \mathrm{m}$

bility. Here, the LDH activity showed that there was no substantial difference between three samples (Table 2).

\section{Discussion}

For the clinical practice in all trials for different cell therapies, some challenges are to overcome in the field of cell biology as well as the material science and encapsulation technology. On the biological side, a crucial need for suitable source of proper cells is inevitable. Stem cells are proper functional cell 


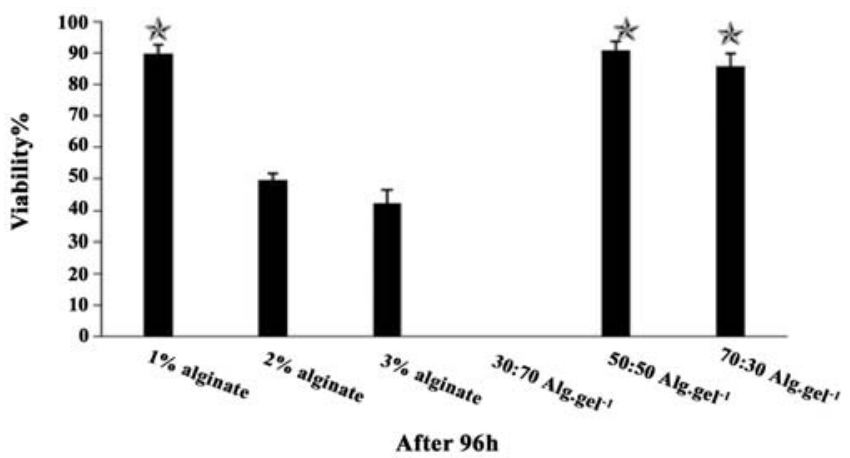

Figure 3. The hADSCs viability in alginate/gelatin composition in comparison with alginate beads considered as the control

sources as opposed to differentiated mature cells. Because of ethical reasons and a lower risk of virus transfer, patient's own cells, especially MSCs are preferred. However, similar to many primary cells, the characteristics of MSCs changed with increasing population doublings. Despite traditional cell culture processes in which a secreted protein or products are desired, the purpose of stem cell cultivation is to expand stem cells and sustain their multipotency, meaning that the functional cell itself is the final product. To date, encapsulation of stem cells in semi-permeable polymeric materials has implemented to enhance cell growth and sustain their multipotency. Moreover, considering the fact that the alginate microcapsule walls protect the cells from the immunological reactions, cell therapy by microencapsulated cells can facilitate its medical application (22). MSCs have the ability to modulate oxidative stress, and secrete various cytokines and growth factors that have immunomodulatory, angiogenic, anti-inflammatory and anti-apoptotic effects. ADSCs are studied as an alternative to bone marrow-derived multipotent stromal cells (BM-MSCs). ADSCs in comparison with BM-MSCs can be isolated more easily; considerably larger amounts of ADSCs can be obtained, in less invasive and safer fashion. Furthermore, the immunomodulatory capacities of ADSCs and AT-MSCs are similar however differences in cytokine secretion cause ADSCs to have more potent immunomodulatory effects than BM-MSCs (23). Therefore, they are an attractive cell source for clinical cell therapy. Another challenge in this regard is the formation of uniform capsules with excellent repeatability and reproducibility. In general, it seems to be a problem that cells agglutinate during encapsulation so that empty beads are produced. One prospect is to distinguish between
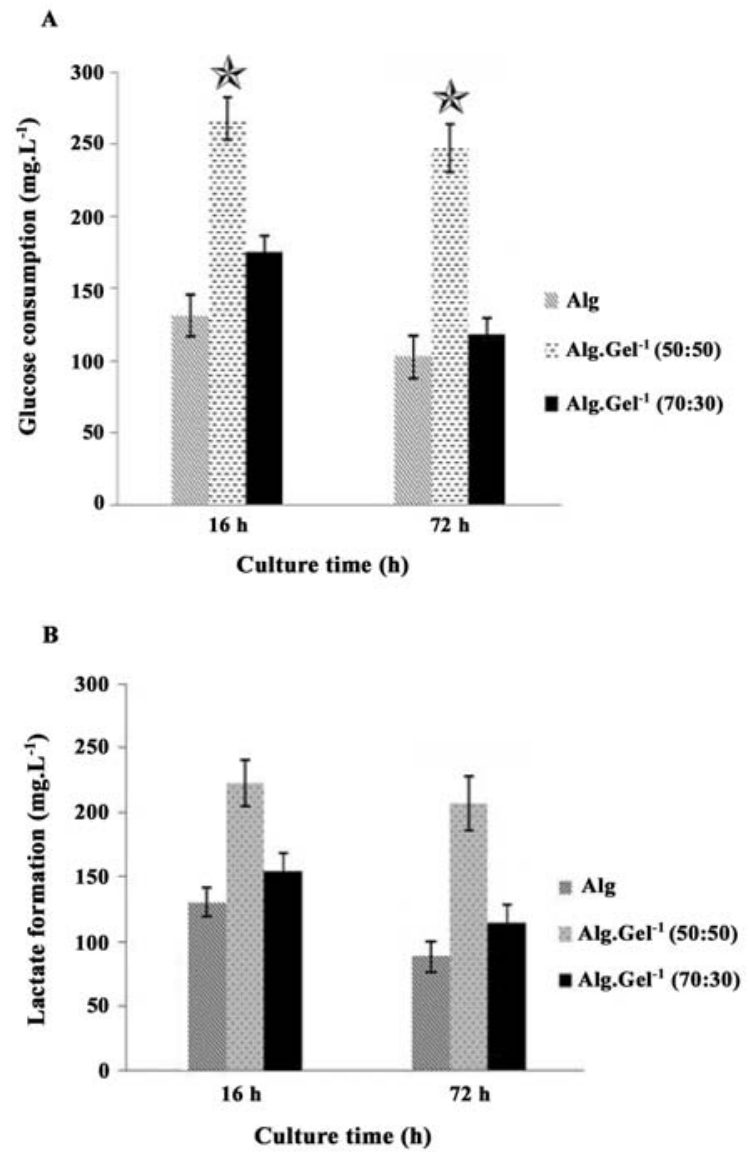

Figure 4. Time-course profile of A: glucose consumption, B: lactate formation in different compositions of alginate/gelatin beads and alginate beads as control

empty and filled capsules. Moreover, many approaches need a defined stability of the cell capsules, which has to be controlled by the material properties. Up to now, it is not possible to create materials with such degradation behaviors.

Alginate is a polysaccharide, which has a frequent medical application. The matrix formed by sodium alginate is a popular technique in cell encapsulation (10). Many parameters have direct effect on alginate beads preparation in order to meet optimum cell growth conditions such as alginate concentration, beads size, and initial cell density. Considering that alginate is a negatively charged polysaccharide, the cells do not desire to adhere to the alginate easily. Thus, mixing alginate biopolymer with the ECM associated biopolymers could improve the cell adhesion and proliferation. Gelatin is a water soluble biopolymer with the high biodegradation rate. Consequently, blending the alginate biopolymer with gelatin could improve the cell proliferation in the generated beads. 
Increasing in the stability of the beads could be due to the increase of the alginate concentration in the composition. On the other hand, high levels of gelatin concentration diminished the beads stability. The alginate/gelatin (30:70) had lower stability in comparison with the beads with the alginate/gelatin ratio of 70:30. Calcium ions as crosslinking agent bind to carboxyl groups of alginates, stabilizing bead structure. Addition of gelatin could disturb this crosslinking process. Although the higher level of alginate concentration increases the stability of the beads, the high level of alginate concentration acts as a barrier to nutrient transfer into the beads and release of toxic by-products from the beads. Consistently, the hADSCs cell viability was reduced in $2 \%$ and $3 \%(\mathrm{w} / \mathrm{v})$ alginate solutions compared to that of the $1 \%$ alginate solution.

Taken together, the main purpose of the current study was to introduce a proper encapsulation method using hydrogels composed of the alginate and gelatin to produce biocompatible beads in order to improve the expansion of the hADSCs for further transplantation and therapeutic applications in the regenerative medicine. While alginate has several advantages for preparing the artificial ECM, gelatin as a natural polymer has a promising application in medicine.

\section{Acknowledgements}

This study was financially supported by Stem Cell Council of I.R of Iran and National Institute of Genetic Engineering and Biotechnology, grant No, 387.

\section{References}

1. Minteer D, Marra KG, Rubin JP. Adipose-derived mesenchymal stem cells: biology and potential applications. Adv Biochem Eng Biotechnol. 2013;59-71. DOI: 10.1007/10 2012146

2. Tsuji W, Rubin JP, Marra KG. Adipose-derived stem cells: Implications in tissue regeneration. World J Stem Cells. 2014;6(3):312. DOI: 10.4252/wjsc.v6.i3.312

3. Maia FR, Fonseca KB, Rodrigues G, Granja PL, Barrias CC. Matrix-driven formation of mesenchymal stem cell-extracellular matrix microtissues on soft alginate hydrogels. Acta Biomater. 2014;10(7):3197-3208. DOI: 10.1016/j.actbio. 2014.02.049

4. Lan S-F, Safiejko-Mroczka B, Starly B. Long-term cultivation of HepG2 liver cells encapsulated in alginate hydrogels: a study of cell viability, morphology and drug metabolism. Toxicol In Vitro. 2010;24(4):1314-1323. DOI: 10.1016/j.tiv. 2010.02.015

5. Han YL, Wang S, Zhang X, Li Y, Huang G, Qi H, et al. Engineering physical microenvironment for stem cell based regenerative medicine. Drug Discov Today. 2014;19(6):763773. DOI: 10.1016/j.drudis.2014.01.015

6. Li X, Liu T, Song K, Yao L, Ge D, Bao C, et al. Culture of neu- ral stem cells in calcium alginate beads. Biotechnol Prog. 2006;22(6):1683-1689.

7. Kuo Y-C, Wang C-C. Guided differentiation of induced pluripotent stem cells into neuronal lineage in alginate-chitosan-gelatin hydrogels with surface neuron growth factor. Colloids Surf B Biointerfaces. 2013;104:194-199. DOI: 10.1016/ j.colsurfb.2013.01.001

8. Ahn S, Lee H, Kim G. Functional cell-laden alginate scaffolds consisting of core/shell struts for tissue regeneration. Carbohydr Polym. 2013;98(1):936-942. DOI: 10.1016/ j.carbpol.2013.07.008

9. Bidarra SJ, Barrias CC, Granja PL. Injectable alginate hydrogels for cell delivery in tissue engineering. Acta Biomater. 2014;10(4):1646-1662. DOI: 10.1016/j.actbio.2013.12. 006

10. Jain D, Bar-Shalom D. Alginate drug delivery systems: application in context of pharmaceutical and biomedical research. Drug Dev Ind Pharm. 2014;40(12):1576-1584. DOI: 10.3109/03639 045.2014.9176 57

11. Wang H, Feng Y, Fang Z, Yuan W, Khan M. Co-electrospun blends of PU and PEG as potential biocompatible scaffolds for small-diameter vascular tissue engineering. Mater Sci Eng C. 2012;32(8):2306-2315. DOI: 10.1016/j.msec.2012.07.001

12. Awad HA, Wickham MQ, Leddy HA, Gimble JM, Guilak F. Chondrogenic differentiation of adipose-derived adult stem cells in agarose, alginate, and gelatin scaffolds. Biomaterials 2004;25(16):3211-3222. DOI: 10.1016/j.biomaterials.2003. 10.045

13. Chong E, Phan T, Lim I, Zhang Y, Bay B, Ramakrishna S, et al. Evaluation of electrospun PCL/gelatin nanofibrous scaffold for wound healing and layered dermal reconstitution. Acta Biomater. 2007;3(3):321-330. DOI: 10.1016/j.actbio.2007.01.002

14. Yu CC, Chang JJ, Lee YH, Lin YC, Wu MH, Yang MC, et al. Electrospun scaffolds composing of alginate, chitosan, collagen and hydroxyapatite for applying in bone tissue engineering. Mater Lett. 2013;93:133-136. DOI: 10.1016/j.matlet. 2012.11.040

15. Lee J, Tae G, Kim YH, Park IS, Kim S-H, Kim SH. The effect of gelatin incorporation into electrospun poly (1-lactide-co- $\varepsilon$ caprolactone) fibers on mechanical properties and cytocompatibility. Biomaterials 2008;29(12):1872-1879. DOI: 10.1016/j. biomaterials.2007.12.029

16. Huang Z-M, Zhang Y, Ramakrishna S, Lim C. Electrospinning and mechanical characterization of gelatin nanofibers. Polymer 2004;45(15):5361-5368. DOI: 10.1016/j.polymer. 2004.04.005

17. Zhao F, Grayson WL, Ma T, Bunnell B, Lu WW. Effects of hydroxyapatite in 3-D chitosan-gelatin polymer network on human mesenchymal stem cell construct development. Biomaterials 2006;27(9):1859-1867. DOI: 10.1016/j.biomaterials.2005.09.031

18. Zeng Q, Han Y, Li H, Chang J. Bioglass/alginate composite hydrogel beads as cell carriers for bone regeneration. J Biomed Mater Res B Appl Biomater. 2014;102(1):42-51. DOI: 10.1002/ jbm.b.32978

19. Radhakrishnan A, Jose GM, Kurup M. PEG-penetrated chitosan-alginate co-polysaccharide-based partially and fully cross-linked hydrogels as ECM mimic for tissue engineering 
applications. Prog Biomater. 2015;4(2-4):101-112. DOI: 6.3585334

20. Wang N, Adams G, Buttery L, Falcone FH, Stolnik S. Alginate encapsulation technology supports embryonic stem cells differentiation into insulin-producing cells. J Biotechnol. 2009;144(4):304-312. DOI:10.1016/j.jbiotec.2009.08.008

21. Wikström J, Elomaa M, Syväjärvi H, Kuokkanen J, Yliperttula M, Honkakoski P, et al. Alginate-based microencapsulation of retinal pigment epithelial cell line for cell therapy. Biomaterials 2008;29(7):869-876. DOI:10.1016/j.biomaterials.2007.10.056

22. Strioga M, Viswanathan S, Darinskas A, Slaby O, Michalek J. Same or not the same? Comparison of adipose tissue-derived versus bone marrow-derived mesenchymal stem and stromal cells. Stem Cells Dev. 2012;21(14):2724-2752. DOI: 10. 1089/scd.2011.0722

23. Melief SM, Zwaginga JJ, Fibbe WE, Roelofs H. Adipose tissue-derived multipotent stromal cells have a higher immunomodulatory capacity than their bone marrow-derived counterparts. Stem Cells Transl Med. 2013;2(6):455-463. DOI: $10.5966 /$ sctm.2012-0184 